\title{
Study of Transected Sciatic Nerve Repair by Biodegradable Membrane and Betamethasone in Adult Albino Wistar Rats
}

\author{
Mehrnaz MOATTARI ${ }^{1}$, Homa Mohseni KOUCHESFEHANI ${ }^{1}$, Gholamreza KAKA ${ }^{2}$, Seyed Homayoon SADRAIE², \\ Majid NAGHDI ${ }^{3}$
}

${ }^{1}$ Kharazmi University, Faculty of Biological Sciences, Department of Animal Biology, Tehran, Iran

${ }^{2}$ Baqiyatallah University of Medical Sciences, Neuroscience Research Center, Tehran, Iran

${ }^{3}$ Fasa University of Medical Sciences, Department of Anatomy, Fasa, Iran

\section{ABSTRACT}

AIM: One of the major injuries of the nervous system is that of peripheral nerves. Although peripheral nerves show some capacity of regeneration after injury, the extent of regeneration is not remarkable. The present study aimed to evaluate the regeneration of the transected sciatic nerve by biodegradable membrane and betamethasone in rats.

MATERIAL and METHODS: Twenty-eight adult male rats were divided into four equal groups including 1. Control group (Ctrl); 2. Betamethasone group (Beta); 3. Membrane group (Mem); 4. Membrane and Betamethasone group (Mem-Beta). Functional recovery was evaluated at 2, 4, 6 and 8 weeks post-surgery. At 8 weeks after surgery, electromyographical (EMG) and histological assessments were performed.

RESULTS: Eight weeks after surgery, sciatic functional index (SFI) and withdrawal reflex latency (WRL) reaction time were decreased significantly $(p<0.05)$ in the Mem+Beta group as compared to the control, beta and Mem groups respectively. The EMG test latency and amplitude of impulses improved in the Mem+Beta group compared to the other groups $(p<0.05)$. Histological assessments performed at 8 weeks after surgery showed a significant increase in the number of nerve fibers, diameter of nerve fibers and myelin thickness in the Mem+Beta group as compared to the Ctrl, Beta and Mem groups $(p<0.05)$.

CONCLUSION: Chitosan membrane together with betamethasone has positive effects on nerve regeneration of the transected sciatic nerve in a rat model.

KEYWORDS: Betamethasone, Biodegradable membrane, Repair, Rats, Sciatic nerve

\section{INTRODUCTION}

$\mathrm{P}$ eripheral nerve injury is a serious and common clinical problem. Although peripheral nerve injuries are not lifethreatening, these injuries impose an economic burden both on the patients and the society. Despite the capacity of peripheral nerves to regenerate after injury, the extent of regeneration is not remarkable $(16,20,30)$. Following nerve injury, scar formation creates a mechanical barrier to the sprouting axons and might inhibit axonal regeneration. Scar formation causes deformities and impairs normal function
(26). Several previous studies have investigated the effects of a range of scar-suppressing drugs and methods such as triamcinolone acetonide (14), triamcinolone hexacetonide (39), collagenase (31), hyaluronic acid-carboxymethyl cellulose membrane (1), aprotinin (12), human amniotic fluid (28), low-dose external beam radiation (13), tissue plasminogen activator (42) or melatonin (36) at the site of a peripheral nerve injury. Recently, the use of appropriate synthetic and natural materials has been studied as alternatives for peripheral nerve repair, and much attention has been given by researchers and clinicians to chitosan. Chitosan is the $\mathrm{N}$-deacetylated 
product of chitin and the second-most abundant natural polysaccharide next to cellulose, which is embedded in a protein matrix of a crustacean shell or a squid pen (33). Chitosan has been studied for a number of useful properties such as biocompatibility, biodegradability, wound healing, antitumor effects and antibacterial properties. It has been shown that chitosan prevents scar formation and provide space for the growth of regenerating axons (41).

The immune system has the ability to play neuroprotective and/or neurodestructive roles following central nervous system or peripheral nervous system injury (19). To maximize the neuroprotective effects of the immune system, steroids were used in the present study. It has been shown that steroid medication suppresses the inflammatory response and consequently causes the migration of macrophages to the site of injury. It is said that using glucocorticoids at the site of a damaged nerve meddle with dilatation capillaries, formation of edema, deposition of fibrin, migration of white cells and phagocytosis. Through the above-mentioned processes, glucocorticoids inhibit inflammation. Macrophages regenerate the damaged nerve in the short term (6 days) $(7,23)$. In addition, steroids prevent lipid peroxidation and retard nerve degeneration after peripheral nerve injury reducing postinjury dysfunction and speed recovery $(9,17)$. Nasser et al. (1996) showed that the use of 21 -aminosteroid by the patients inhibits the lipid peroxidation and thus has a protective effect on the crush injury of the nerve (25). The beneficial effects of betamethasone on the crushed sciatic nerve injury were shown by Al-Bishri et al. in 2005 (2). In addition, use of methylprednisolone can produce a significant improvement in sensation and motor function (5). Sadraie et al. (2016) reported that use of amniotic membrane and betamethasone have positive effects on nerve regeneration of the transected sciatic nerve in a rat model (27). A synthetic product of glucocorticoids, betamethasone, is often used in oral and maxillofacial surgery to reduce inflammation. Therefore, in the present study, we examined the effects of biodegradable chitosan membrane wrapping impregnated with betamethasone on the sciatic nerve functional recovery and nerve regeneration.

\section{- MATERIAL and METHODS}

\section{Animals}

Twenty-eight adult male Wistar rats weighing 180-200 g purchased from the Pasteur Institute Tehran, Iran ( $n=7 /$ group) were used in the present experimental study. The animals were kept in plastic cages under a 12/12 hour light/dark cycle, at controlled temperature $23 \pm 2^{\circ} \mathrm{C}$ and $50 \%$ humidity with free access to water and standard rat chow (Behparvar Com, Iran). All experiments involving animals and surgical procedures were approved by the Ethical Committee of Baqiyatallah University of Medical Sciences.

\section{Membrane Preparation}

Thin films of chitosan were prepared with a mixture of $0.25 \mathrm{~g}$ of chitosan and $0.08 \mathrm{~g}$ polyethylene oxide (PEO) dissolved in $50 \mathrm{ml}$ of $1 \%$ acetic acid solution. The mixture was stirred for two hours at $40^{\circ} \mathrm{C}$. The resultant solution was centrifuged at
2500 rpm for 10 minutes to prevent air bubbles from forming. The mixture was cast into plastic Petri dishes with $75 \mathrm{~mm}$ diameter, dried at $25^{\circ} \mathrm{C}$ for 24 hours. The films were then dried and cut to patches of $1 \mathrm{~cm} \times 1 \mathrm{~cm}$ in size (Figure 1A).

\section{Experiment Groups}

In this experimental study, twenty-eight rats were randomly divided into four equal groups ( $n=7 /$ group) including 1 ) Control group (Ctrl): (sciatic nerve of rats transected and sutured without any additional treatment); 2) Betamethasone group (Beta): (0.2 $\mathrm{ml}$ Betamethasone $4 \mathrm{mg} / \mathrm{ml}$ was injected in the site of transected and sutured sciatic nerve of rats); 3) Membrane group (Mem): chitosan membrane was wrapped around the transected and sutured sciatic nerve of rats); 4) Mem+Beta group: (chitosan membrane impregnated with $0.2 \mathrm{ml}$ betamethasone $4 \mathrm{mg} / \mathrm{ml}$ was wrapped around the transected and sutured sciatic nerve of rats).

\section{Surgical Procedure}

All animals were anesthetized by intraperitoneal injection of $80 \mathrm{mg} / \mathrm{kg}$ ketamine hydrochloride (Alfasan, Netherlands) and $5 \mathrm{mg} / \mathrm{kg}$ xylazine hydrochloride (Alfasan, Netherlands) intraperitoneally. To dissect the sciatic nerve, the right hind limb was shaved and a $3 \mathrm{~cm}$ longitudinal cutaneous incision made in the posterolateral side of the thigh to expose the sciatic nerve. The right sciatic nerve was transected at the midway by a sharp surgical knife (Figure 1B). The epineurium of transected nerve was sutured with size 7.0 Prolene sutures and the muscle fascia and skin sutured with size 4.0 nylon sutures (Figure 1C).

\section{Sciatic Functional Index (SFI) Assessment}

SFI was measured using an apparatus apparatus made from wood with $60 \times 7 \times 20 \mathrm{~cm}$ dimensions and its floor was covered with white paper. Functional recovery was assessed at 2, 4, 6 and 8 weeks after surgery. Before the test, the rats' paws were painted with a water soluble blue ink, and then the rats were permitted to walk through the apparatus and their foot prints were tracked. The lengths of the third toe to its heel (PL), the second toe to the fourth toe (IT), and the first to the fifth toe (TS) were measured on the contralateral normal $(\mathrm{N})$, and the experimental side (E). SFI was computed by the following modified formula:

$$
\begin{gathered}
\mathrm{SFI}=\mid-38.5(\text { EPL-NPL/NPL) }+109.5 \text { (ETS-NTS/NTS) }+13.3 \\
\text { (EIT-NIT/NIT)-8.8 } \mid
\end{gathered}
$$

In this study, SFI oscillates around 0 for normal nerve function, and around $100 \mathrm{SFI}$ for transected nerve function which represents total motor sciatic nerve dysfunction (37).

\section{Withdrawal Reflex Latency (WRL) Assessment}

The WRL test was performed using the hot water bath (DID SABZ Co. Iran). The water temperature was set at $50 \pm 1^{\circ} \mathrm{C}$. Paw withdrawal was measured reaction time in the hot water paw immersion test was done at 2, 4, 6 and 8 weeks after surgery. The Paw immersion procedure was as follows: each rat was gently caught from the back by the experimenter and one of its feet (i.e. intact or experimental) immersed into hot water till its paw's reaction. The time the rat withdraws its paw 
from the water was recorded and expressed as the reaction time.

\section{Electromyographical (EMG) Evaluation}

At 8 weeks after surgery, the sciatic nerves were exposed in the anesthetized rats. The stainless steel electrodes were placed in the proximal site of the injured nerve and electrical impulses with duration of $0.1 \mathrm{~ms}$ and intensity of $2.3 \mathrm{~mA}$ were applied. Amplitude and latency of the impulses were recorded as the factors of nerve conductivity from the gastrocnemius muscle and a reference cap electrode inserted on the knee joint. Another stainless steel needle, which was inserted into the tail skin, was used as the ground electrode (40).

\section{Histological Analysis}

For histological assessment, 8 weeks after surgery, the sciatic nerves were surgically taken out and fixed in $10 \%$ formalin and embedded in paraffin. Five $\mu \mathrm{m}$ transverse sections from distal portion of sciatic nerves were then stained by hematoxylin and eosin using standard techniques. The number of nerve fibers in different categories based on the diameter (including $>6 \mu \mathrm{m}, 4-6 \mu \mathrm{m}$ and $<4 \mu \mathrm{m}$ diameters), diameter of nerve fiber, axon diameter and myelin thickness were evaluated from at least 5 randomly selected area using MOTIC software (Nikon, Japan, 2001) under light microscopy from at least 5 randomly selected at $1000 \times$ magnification.

\section{Statistical Analysis}

All data were expressed as mean \pm standard deviation (SD). Results were analyzed using one-Way analysis of variance (ANOVA) followed by least significant different (LSD) Post Hoc test (SPSS 22.0 software package, SPSS Inc., Chicago, IL). A difference less than $0.05(p<0.05)$ level was considered as statistically significant.

\section{RESULTS}

\section{SFI Evaluations}

After surgery, the SFI values after surgery in all surgical groups were significantly increased. At 8 weeks after surgery, SFI decreased significantly and improvement was found in Mem+Beta group compared to Ctrl, Beta and Mem groups respectively $(p=0.001, p=0.01$ and $p=0.04$ ) (Figure 2$)$.
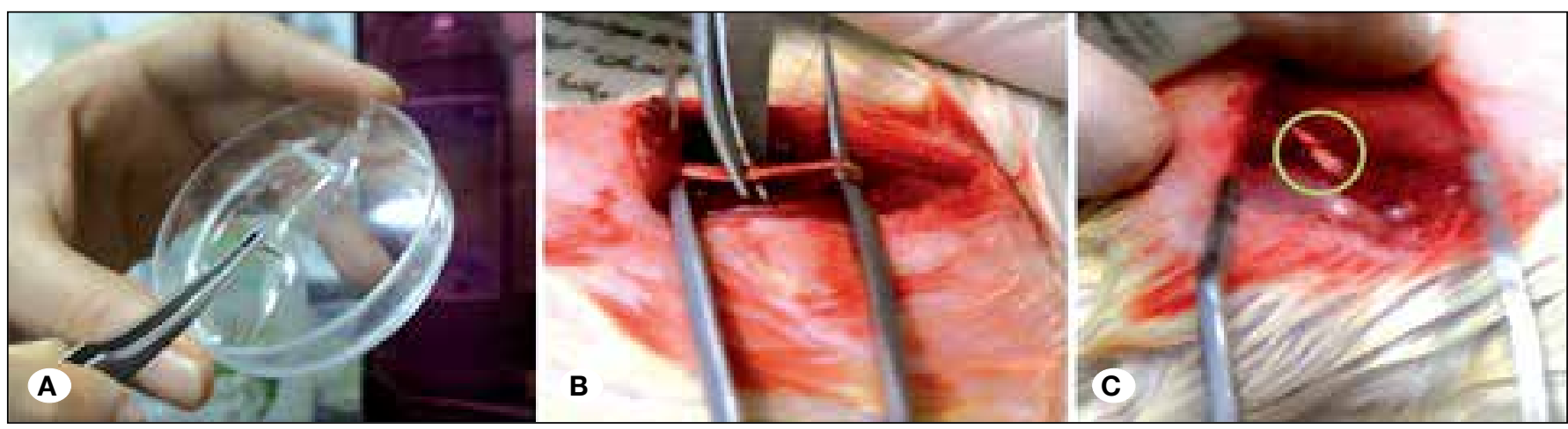

Figure 1: A) Preparation of membrane, B) sciatic nerve transection and C) suturing of the animals. Right sciatic nerves were sectioned under germfree conditions and sutured through the epineurium.

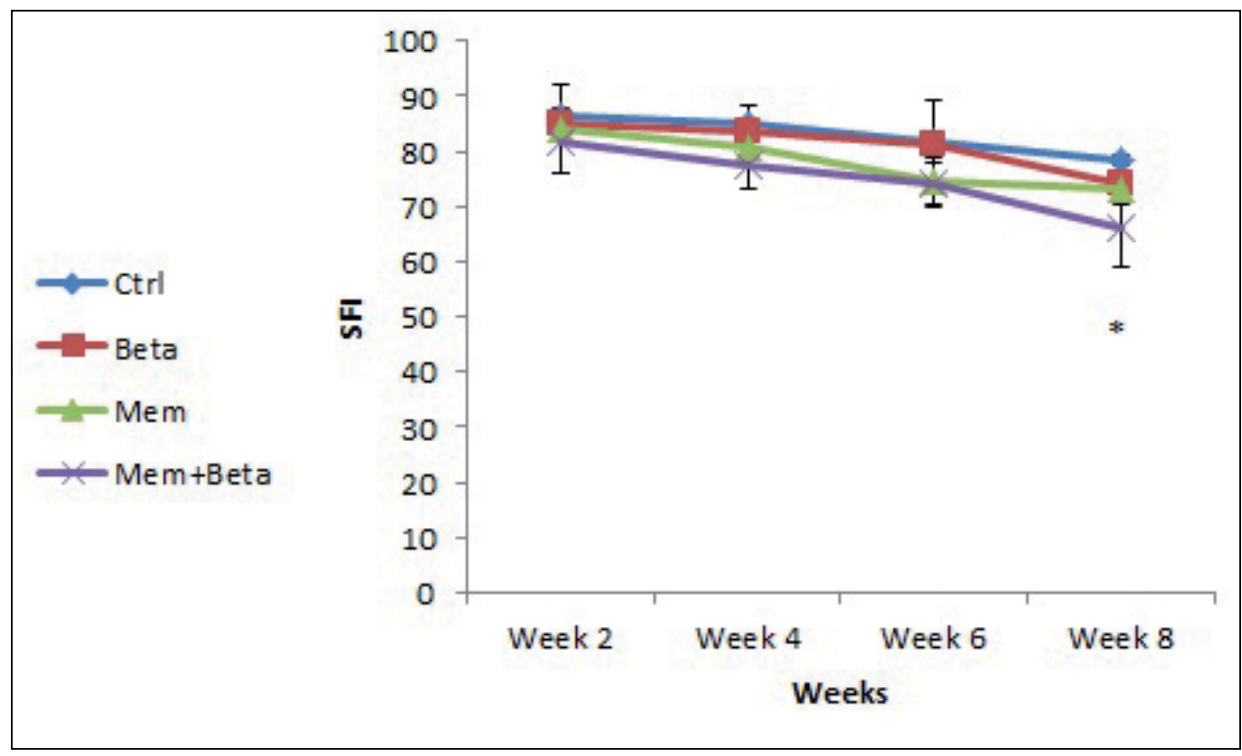

Figure 2: Comparison of the mean functional recovery of SFI $($ mean $\pm S D)$. At 8 weeks after surgery, SFI decreased significantly and improvement was found in Mem+Beta group compared to control and sham group $(p<0.05)$. 


\section{WRL Results}

At 8 weeks after surgery, the reaction time in WRL test significantly decreased in therapeutic groups especially in the Mem+Beta group compared with control, Beta and Mem groups $(p=0.001, p=0.04, p=0.04)$ (Figure 3 ).

\section{EMG Results}

Our data showed the mean of latency (ms) in Mem-Beta group $(1.7 \pm 0.20)$ were significantly decreased compared to Ctrl (2.53 \pm 0.27$)$, Beta $(2.37 \pm 0.42)$ and Mem $(2.25 \pm 0.25)$ groups, $(\mathrm{p}=0.001, \mathrm{p}=0.01$ and $\mathrm{p}=0.04$, respectively). In addition, at 8 weeks after surgery, the mean of amplitude $(\mathrm{mV})$ in Mem+Beta group $(4.90 \pm 0.52)$ were significantly increased compared to control $(3.57 \pm 0.53)$, Beta $(4.00 \pm 0.50)$ and Mem $(4.1 \pm 0.47)$ groups, $(p=0.001, p=0.007$ and $p=0.02$ respectively) (Figures 4-6).

\section{Histomorphometric Results}

At 8 weeks after surgery, the numbers of nerve fibers in different categories based on diameter in the surgical groups significantly decreased compared to intact group. The mean number of nerve fibers in more than $6 \mu \mathrm{m}$ non-significantly in Mem-Beta group compared to Ctrl, Beta and Mem group. Mean number of nerve fibers with 4 to $6 \mu \mathrm{m}$ diameter increased significantly in Mem+Beta group compared to control, Beta and Mem+Beta groups, respectively In the category which has 4 to $6 \mu \mathrm{m}$ diameter, the number of nerve fibers increased significantly in Mem+Beta group compared to control, Beta and Mem+Beta groups $(p=0.001, p=0.01$ and $p=0.04$, respectively). Mean number of nerve fibers with less than 4 $\mu \mathrm{m}$ non-significantly increased in Mem+Beta group compared to control, Beta and Mem+Beta groups (Figure 7). However, no significant differences were found in diameters of myelin and axons in Mem+Beta group compared to control group.
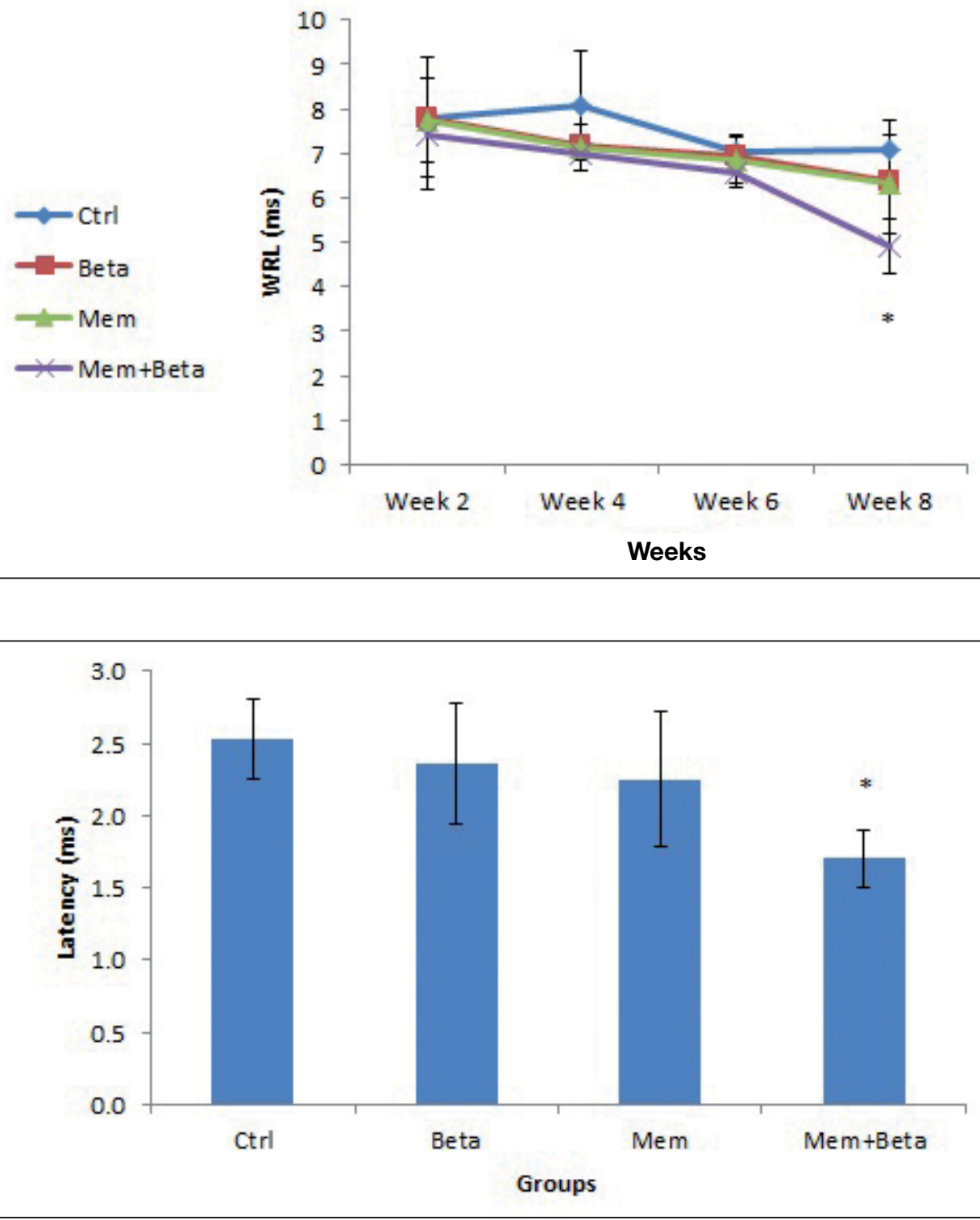

Figure 3: Results of hot water paw immersion test (mean \pm SD). At 8 weeks after surgery, the reaction time in hot plate test decreased significantly in Mem+Beta $(p<0.05)$.
Figure 4: Comparison of mean latency (ms) analysis in all experimental groups (mean $\pm \mathrm{SD}$ ). Latency analyses decreased significantly in Mem-Beta treated group compared to control and sham groups at 8 weeks after surgery $(p<0.05)$. 

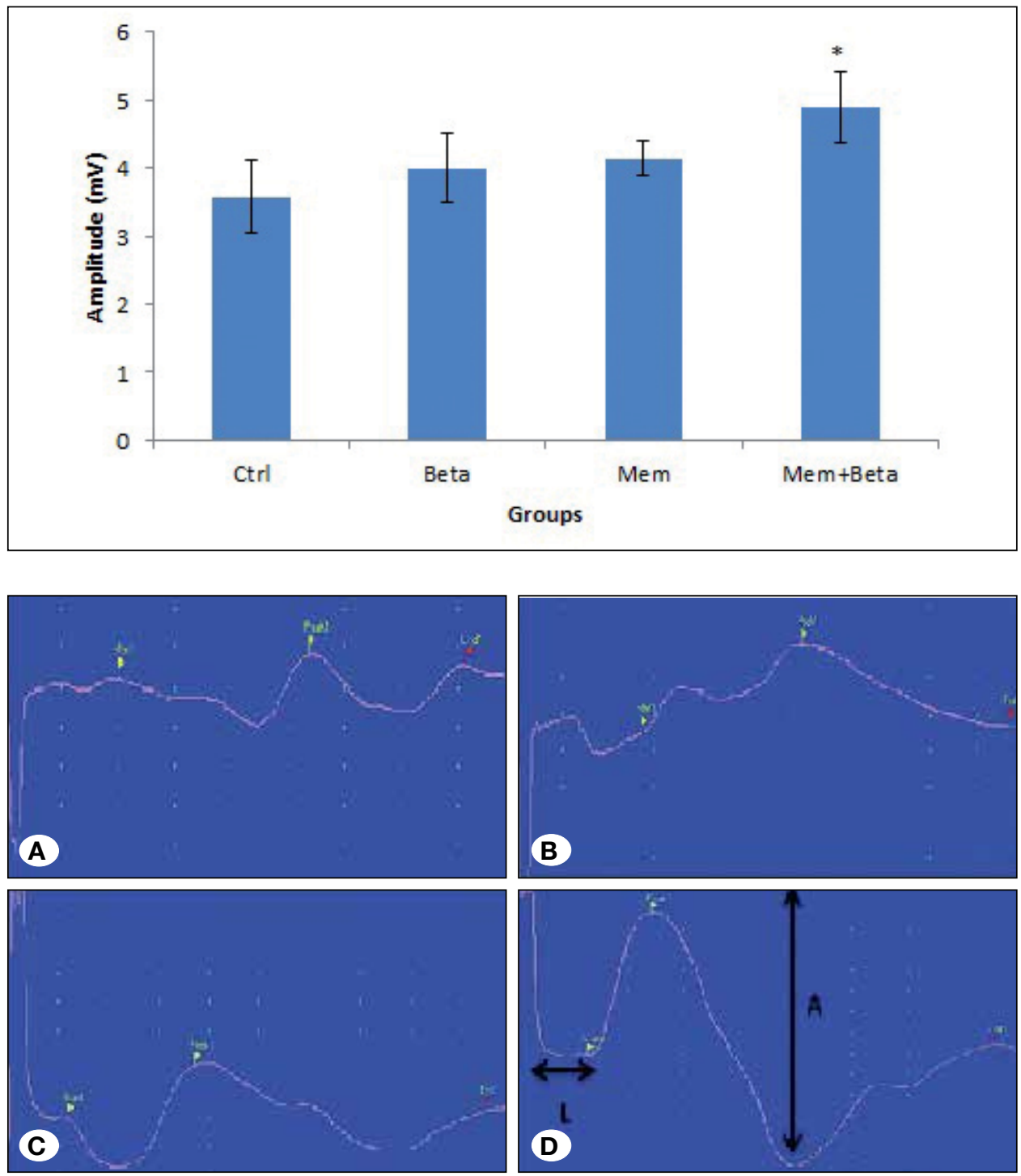

Figure 6: Electromyographic waves for Ctrl, Beta, Mem and Mem+Beta groups 8 weeks after surgery. L: Latency and A: Amplitude.
Figure 5: Comparison of mean amplitude $(\mathrm{mV})$ analysis in all experimental groups (mean $\pm S D)$. Amplitude was increased significantly in Mem+Beta treated group compared to control and sham groups at 8 weeks after surgery $(p<0.05)$.

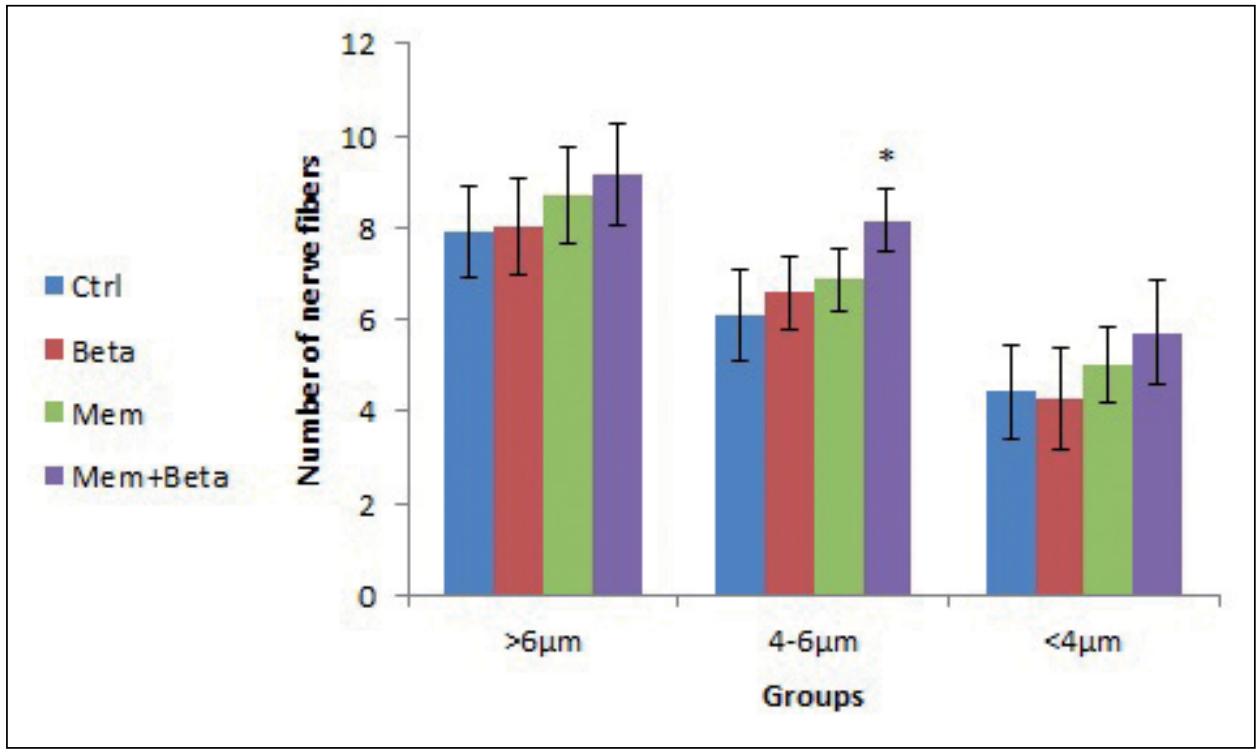

Figure 7: Number of nerve fibers is shown in different categories based on diameter (mean $\pm \mathrm{SD}$ ). In category which have 4 to 6 diameter, the number of nerve fibers increased significantly in Mem+Beta group compared to control, Beta and MemBeta groups, respectively $(p<0.05)$. 
However, no significant differences were found in diameters of axons in Mem+Beta group compared to other groups (Figure 8). Diameter of nerve fibers and thickness of myelin was also significantly increased in Mem+Beta group compared to control, Beta and Mem+Beta groups (Figures 9,10).

\section{DISCUSSION}

Peripheral nerve injuries impose an economic burden both on the patients and the society, although these injuries are not life-threatening (30). The currently available surgical treatment options for different types of nerve injuries in clinical conditions consist of direct nerve repair and grafting or tubulization. Direct nerve repair (end-to-end techniques) is the common surgical approach for simple injuries without gaps or when the gap is short (5 mm or less). For longer nerve gaps, when nerve injury has resulted in substance loss between the two nerve stumps, nerve grafting or tubulization techniques must be used to bridge the gap because direct suturing under tension leads to very poor clinical results. As an alternative for bridging short nerve defects without the morbidities associated with harvesting of autologous nerve grafts, tubulization techniques with natural or artificial conduits are applicable (35).

The assessment of sciatic nerve regeneration based on SFI, hot water foot immersion test, electrophysiological and histomorphometric studies have shown that the use of chitosan and betamethasone could be useful for repair of transected sciatic nerve to enhance rat sciatic nerve regeneration.

Based on a literature review, most of the functional recovery occurred between 14 and 90 days post-operation $(8,11)$. In many previous studies, investigations have been performed 4,6 or 8 weeks after surgery $(2,11,15,38)$. Data indicates that
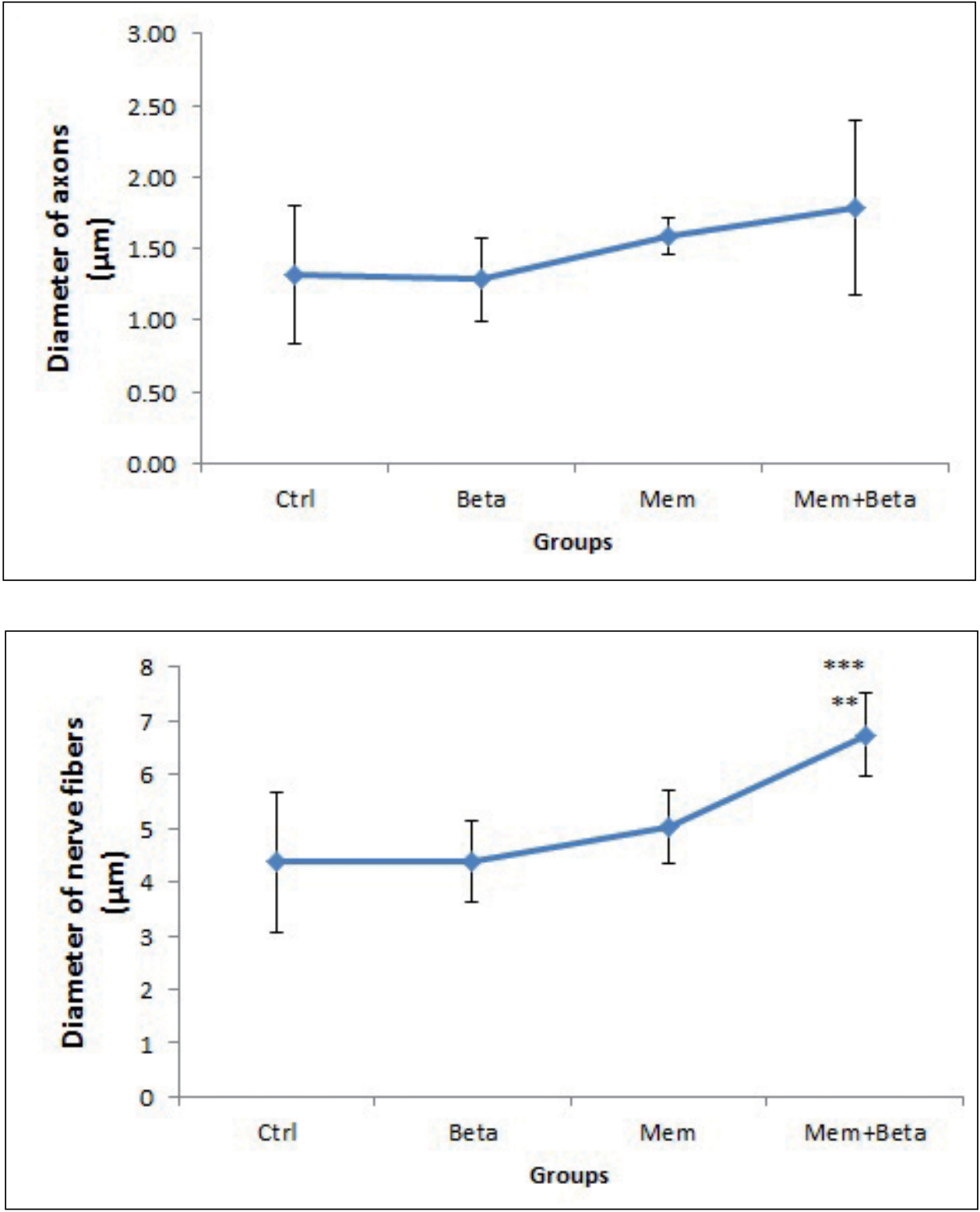

Figure 8: Morphometric analyses of regenerated nerves for each experimental groups at 8 weeks after surgery (mean $\pm S D)$. There is no significant differences among groups.
Figure 9: Morphometric analyses of regenerated nerves for each experimental groups at 8 weeks after surgery (mean $\pm \mathrm{SD})$. ${ }^{\star *}$, ${ }^{\star \star *}$ shows that diameter of nerve fibers increased significantly in Mem+Beta group compared to Ctrl and Beta and Mem groups $(p<0.001, p<0.001$ and $\mathrm{p}<0.01)$. 
Wallerian degeneration begins within hours of injury and is complete by 6-8 weeks (6). Previous studies confirmed that regeneration of myelinated nerve fibers notably occurred 4-12 weeks after surgery. The electrophysiological analysis was also performed 8 weeks after the surgery, based on the literatures suggesting sciatic nerve regeneration 4 to 8 weeks after surgical reconstruction (10). Furthermore, it was demonstrated that by 7 weeks, the re-growing axons have reached the gastrocnemius muscle, the tibialis anterior muscles and the soleus muscles (15).

Our data demonstrated that at 8 weeks after surgery, SFI and WRL results improved significantly in the Mem+Beta group. Our findings are in agreement with the results of Amado et al. who reported that chitosan membrane significantly improved post-traumatic axonal regrowth and functional recovery after

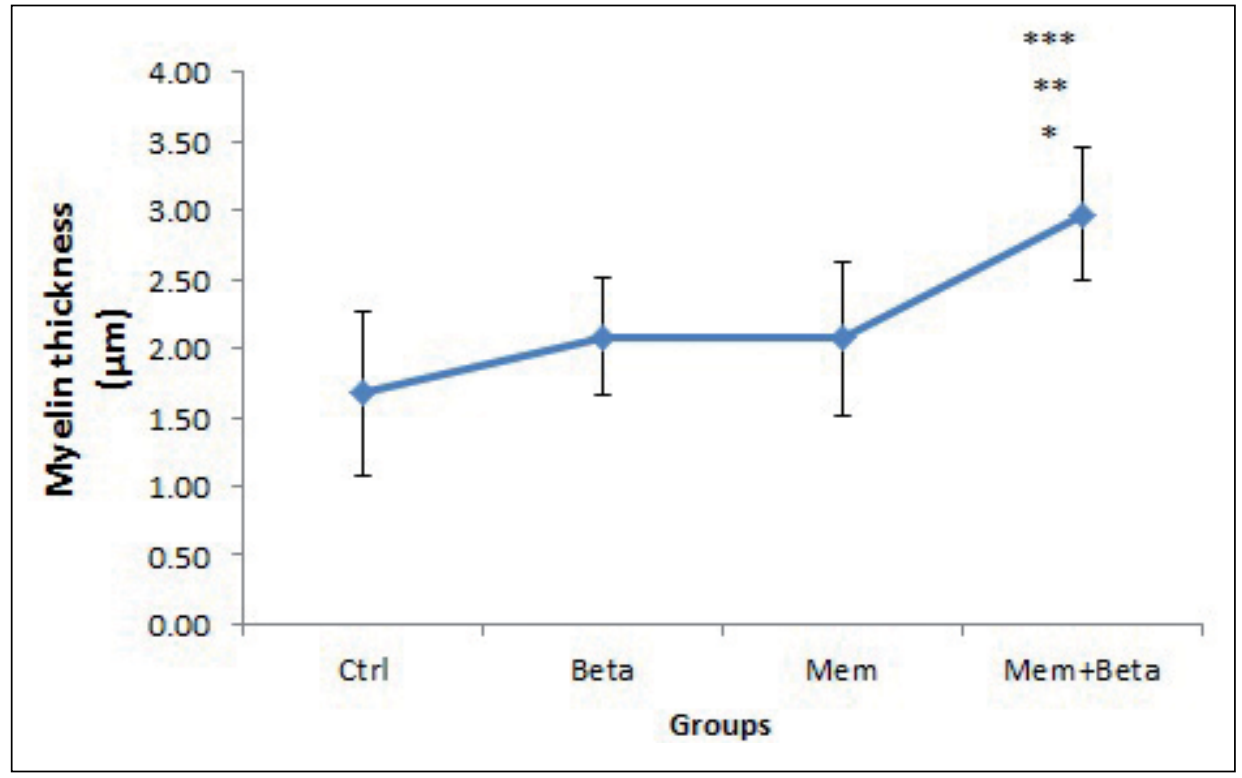

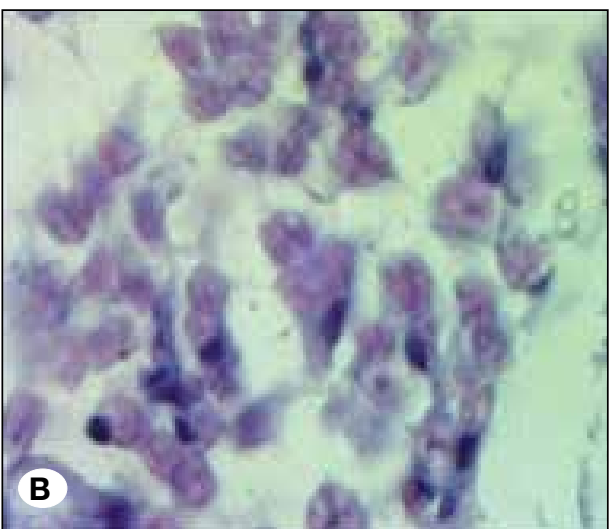

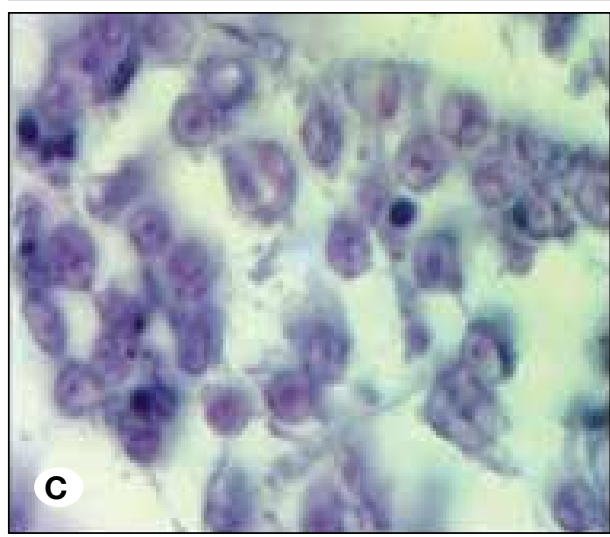

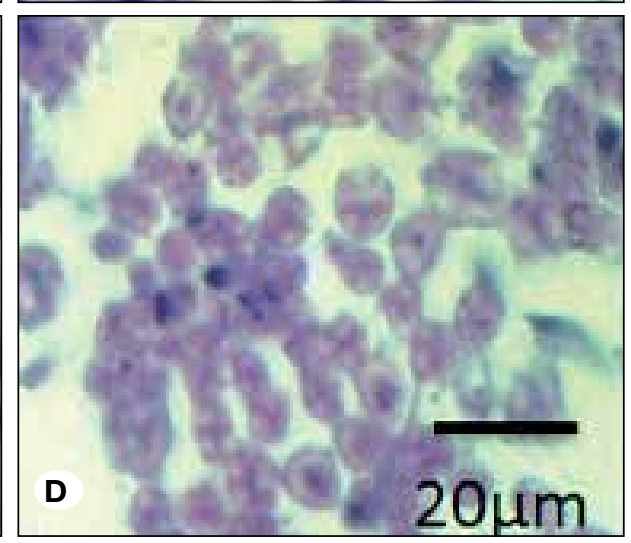

Figure 10: Morphometric analyses of regenerated nerves for each experimental group at 8 weeks after surgery (mean $\pm \mathrm{SD}){ }^{*}{ }^{*}{ }^{* \star *}$ shows that thickness of myelin increased significantly in Mem+Beta groups compared to Ctrl, Beta and Mem+Beta groups $(p<0.001, p<0.001$ and $p<0.05)$.
Figure 11: Photomicrographs of cross sections through distal part of damaged sciatic nerve at 8 weeks after surgery in different groups.

A) Ctrl group, B) Beta group, C) Mem group and D) Mem+Beta group. (Hematoxylin and eosin, $\times 1000$ ) 
crush injury (3). In addition, Raisi et al. reported that functional recovery was better in the chitosan group than the silicone group 8 weeks after surgery (29). Sadraie et al. also reported that behavioral analyses (SFI and WRL) in the amniotic membrane and betamethasone group improved significantly compared to control and sham groups (32).

Our findings showed that at 8 weeks after surgery, EMG results improved significantly in Mem+Beta group. Our findings agree with the results of Azizi et al. who reported that conduction velocity was better in the alpha-lipoic acid and the chitosan group than control group (4). The results of Sadraie et al. showed that electrophysiological indices in amniotic membrane and the betamethasone groups improved significantly compared to the Ctrl and sham groups (32).

In addition, our data revealed that at 8 weeks after surgery, histomorphometric results improved significantly in Mem+Beta group (Figure 11 A-D). Our findings agree with the results of Lin et al. who reported that the number of regenerated axons was higher in chitosan group than control group (21). Sadraie et al. reported that use of amniotic membrane and betamethasone group have positive effects on histomorphometric values compared to control and sham groups (32). Shirosaki et al. reported that using chitosan- $\gamma$-glycidoxypropyltrimethoxysilane (chitosan-GPTMS) porous hybrid membranes improved histomorphological and functional recovery after 12 weeks (34). In this research, we studied the effect of biodegradable membrane and betamethasone on the regeneration of sciatic nerves after transection. The results suggest that Mem+Beta promoted the regeneration of sciatic nerve after transection injury. Use of Mem+Beta in the early postsurgical period (inflammatory phase) accelerated recovery of regenerated nerve fibers. On the other hand, the process of fiber myelination and increase of myelin thickness showed the benefits of the Mem+Beta in early fiber myelination of regenerated nerves in treated groups compared to other groups. Myeline thickness is suggestive of a multifocal inflammatory demyelinating process.

Marcol et al. demonstrated that use of chitosan on the site of nerve transection has beneficial influence on the development of post-traumatic neuroma and reduction of extraneural fibrosis (22). As a scaffold, chitosan avoids scar formation and provides a suitable microenviroment for axon regeneration. On the other hand, there is a correlation between blood vessels (number and size of blood vessels) and axonal regeneration. It is shown that chitosan stimulates angiogenesis by promoting endothelial sprouting which produces a suitable environment for axon growth and increases nerve regeneration (18).

It is reported that chitosan enhances the production of TGF-b1 and platelet-derived growth factor (PDGF) and IL-1 by stimulating macrophages (41). In injured peripheral nerves, the entry of macrophages and their activation leads to phagocytosis of debris, followed by their clearance from the nerve (17). This well-coordinated sequence of macrophage responses prepare the distal segment to receive regenerating axon sprouts. The macrophage response terminates by down-regulation of pro-inflammatory cytokines and the up-regulation of antiinflammatory ones. It has been shown that steroid medication prevents inflammatory response and lipid peroxidation. This inhibition decreases functional dysfunction after peripheral nerve injury and accelerates nerve regeneration (24).

\section{CONCLUSION}

According to the findings of this study, it can be concluded that using chitosan wrapping impregnated with betamethasone may improve the clinical outcome related to sciatic nerve function and regeneration somewhat but the result is often unsatisfactory and there is rarely a complete return of function.

\section{ACKNOWLEDGEMENT}

This study was supported by Neuroscience Research Center, Baqiyatallah University of Medical Sciences.

\section{REFERENCES}

1. Adanali G, Verdi M, Tuncel A, Erdogan B, Kargi E: Effects of hyaluronic acid-carboxymethylcellulose membrane on extraneural adhesion formation and peripheral nerve regeneration. J Reconstr Microsurg 19: 29-36, 2003

2. Al-Bishri A, Dahlin L, Sunzel B, Rosenquist J: Systemic betamethasone accelerates functional recovery after a crush injury to rat sciatic nerve. J Oral Maxillofac Surg 63: 973-977, 2005

3. Amado S, Simoes MJ, Armada da Silva PA, Luis AL, Shirosaki Y, Lopes MA, Santos JD, Fregnan F, Gambarotta G, Raimondo S, Fornaro M, Veloso AP, Varejao AS, Mauricio AC, Geuna S: Use of hybrid chitosan membranes and N1E-115 cells for promoting nerve regeneration in an axonotmesis rat model. Biomaterials 29: 4409-4419, 2008

4. Azizi S, Heshmatian B, Amini K, Raisi A, Azimzadeh M: Alphalipoic acid loaded in chitosan conduit enhances sciatic nerve regeneration in rat. Iran J Basic Med Sci 18: 228-233, 2015

5. Bracken MB, Shepard MJ, Collins WF, Holford TR, Young W, Baskin DS, Eisenberg HM, Flamm E, Leo-Summers L, Maroon $\mathrm{J}$ : A randomized, controlled trial of methylprednisolone or naloxone in the treatment of acute spinal-cord injury: Results of the Second National Acute Spinal Cord Injury Study. N Engl J Med 322: 1405-1411, 1990

6. Campbell WW: Evaluation and management of peripheral nerve injury. Clin Neurophysiol 119(9): 1951-1965, 2008

7. Dahlin LB, Miyauchi A, Thomsen P, Danielsen N, Kanje $M$ : Stimulation of nerve regeneration by macrophages in granulation tissue. Restor Neurol Neurosci 9: 141-149, 1996

8. Farjah $\mathrm{GH}$, Dolatkhah MA, Pourheidar B, Heshmatian B: The effect of cerebrospinal fluid in collagen guide channel on sciatic nerve regeneration in rat. Turk Neurosurg 27(3): 453459, 2017

9. Galloway EB, Jensen RL, Dailey AT, Gregory Thompson B, Shelton C: Role of topical steroids in reducing dysfunction after nerve injury. Laryngoscope 110: 1907-1910, 2000

10. Georgiou M, Golding JP, Loughlin AJ, Kingham PJ, Phillips JB: Engineered neural tissue with aligned, differentiated adiposederived stem cells promotes peripheral nerve regeneration across a critical sized defect in rat sciatic nerve. Biomaterials 37: 242-251, 2015

11. Gocmen S, Sirin S, Oysul K, Ulas UH, Oztas E: The effects of low-dose radiation in the treatment of sciatic nerve injury in rats. Turk Neurosurg 22:167-173, 2012 
12. Gorgulu A, Imer M, Simsek O, Sencer A, Kutlu K, Cobanoglu $S$ : The effect of aprotinin on extraneural scarring in peripheral nerve surgery: An experimental study. Acta Neurochir (Wien). 140:1303-1307, 1998

13. Gorgulu A, Uzal C, Doganay L, Imer M, Eliuz K, Cobanoglu S: The effect of low-dose external beam radiation on extraneural scarring after peripheral nerve surgery in rats. Neurosurgery 53: 1389-1396, 2003

14. Graham III WP, Davis TS, Miller SH, Rusenas I: Efficacy of triamcinolone acetonide following neurorrhaphy-an electroneuromyographic evaluation. Ann Plast Surg 9: 230237, 1982

15. Gramsbergen A, IJkema-Paassen J, Meek M: Sciatic nerve transection in the adult rat: Abnormal EMG patterns during locomotion by aberrant innervation of hindleg muscles. Exp Neurol 161: 183-193, 2000

16. Grinsell D, Keating C: Peripheral nerve reconstruction after injury: A review of clinical and experimental therapies. BioMed Res Int 2014:698256, 2014

17. Hall ED: The effects of glucocorticoid and nonglucocorticoid steroids on acute neuronal degeneration. Adv Neurol 59: 241248, 1992

18. Hobson MI, Green CJ, Terenghi G: VEGF enhances intraneural angiogenesis and improves nerve regeneration after axotomy. J Anat 197: 591-605, 2000

19. Jones KJ, Serpe CJ, Byram SC, DeBoy CA, Sanders VM: Role of the immune system in the maintenance of mouse facial motoneuron viability after nerve injury. Brain Behav Immun 19:12-19, 2005

20. Lee SK, Wolfe SW : Peripheral nerve injury and repair. J Am Acad Orthop Surg 8: 243-252, 2000

21. Lin YL, Jen JC, Hsu SH, Chiu IM: Sciatic nerve repair by microgrooved nerve conduits made of chitosan-gold nanocomposites. Surg Neurol 70 Suppl 1:S1:9-18, 2008

22. Marcol W, Larysz-Brysz M, Kucharska M, Niekraszewicz A, Slusarczyk W, Kotulska K, Wlaszczuk P, Wlaszczuk A, Jedrzejowska-Szypulka H, Lewin-Kowalik J: Reduction of post-traumatic neuroma and epineural scar formation in rat sciatic nerve by application of microcrystallic chitosan. Microsurgery 31: 642-649, 2011

23. Miyauchi A, Kanje M, Danielsen N, Dahlin LB: Role of macrophages in the stimulation and regeneration of sensory nerves by transposed granulation tissue and temporal aspects of the response. Scand J Plast Reconstr Surg Hand Surg 31: 17-23, 1997

24. Mohammadi R, Amini K, Eskafian H: Betamethasoneenhanced vein graft conduit accelerates functional recovery in the rat sciatic nerve gap. J Oral Maxillofac Surg 71: 786-792, 2013

25. Nasser RM, Chen LE, Seaber AV, Urbaniak JR: Protective effect of 21-aminosteroid pretreatment in peripheral nerve low-load crush injury in mature and immature rats. J Orthop Res 14: 823-829, 1996

26. O'Kane S, Ferguson MW: Transforming growth factor $\beta$ s and wound healing. Int J Biochem Cell Biol 29: 63-78, 1997

27. Ozbek Z, Aydin HE, Kocman AE, Ozkara E, Sahin E, Bektur E, Vural M, Kose A, Arslantas A, Baycu C: Neuroprotective effect of genistein in peripheral nerve injury. Turk Neurosurg 27(5):816-822, 2017

28. Ozgenel GY, Filiz G: Effects of human amniotic fluid on peripheral nerve scarring and regeneration in rats. J Neurosurg 98: 371-377, 2003
29. Raisi A, Azizi S, Delirezh N, Heshmatian B, Amini K: Use of chitosan conduit for bridging small-gap peripheral nerve defect in sciatic nerve transection model of rat. Iran J Vet Surg 5: 89-100, 2012

30. Rosberg HE, Carlsson KS, Cederlund RI, Ramel E, Dahlin LB: Costs and outcome for serious hand and arm injuries during the first year after trauma-a prospective study. BMC Public Health 13:501, 2013

31. Rydevik M, Bergström F, Mitts C, Danielsen N: Locally-applied collagenase and regeneration of transsected and repaired rat sciatic nerves. Scand J Plast Reconstr Surg Hand Surg 36: 193-196, 2002

32. Sadraie SH, Parivar K, Arabi F, Moattari M, Kaka G, Mansouri $\mathrm{K}$ : Study of transected sciatic nerve repair by amniotic membrane with betamethasone in adult albino wistar rats. Arch Iran Med 19(9): 612-617, 2016

33. Shahram E, Sadraie SH, Kaka G, Khoshmohabat H Hosseinalipour M, Panahi F, Naimi-Jamal MR: Evaluation of chitosan-gelatin films for use as postoperative adhesion barrier in rat cecum model. Int J Surg 11: 1097-1102, 2013

34. Shirosaki Y, Hayakawa S, Osaka A, Lopes MA, Santos JD, Geuna S, Mauricio AC: Challenges for nerve repair using chitosan-siloxane hybrid porous scaffolds. Biomed Res Int 2014:153808, 2014

35. Siemionow M, Brzezicki G: Current techniques and concepts in peripheral nerve repair. Int Rev Neurobiol 87: 141-172, 2009

36. Turgut M, Uysal A, Pehlivan M, Yurtseven M: Assessment of effects of pinealectomy and exogenous melatonin administration on rat sciatic nerve suture repair: An electrophysiological, electron microscopic, and immunohistochemical study. Acta Neurochir (Wien) 147: 67-77, 2005

37. Yao M, Zhou Y, Xue C, Ren H, Wang S, Zhu H, Gu X, Gu X, Gu $\mathrm{J}$ : Repair of rat sciatic nerve defects by using allogeneic bone marrow mononuclear cells combined with chitosan/silk fibroin scaffold. Cell Transplant 25: 983-993, 2016

38. Yarar E, Kuruoglu E, Kocabıcak E, Altun A, Genc E, Ozyurek H, Kefeli M, Marangoz AH, Aydın K, Cokluk C: Electrophysiological and histopathological effects of mesenchymal stem cells in treatment of experimental rat model of sciatic nerve injury. Int J Clin Exp Med 8: 8776,2015

39. Yates JM, Smith KG, Robinson PP: The effect of triamcinolone hexacetonide on the spontaneous and mechanically-induced ectopic discharge following lingual nerve injury in the ferret. Pain 111: 261-269, 2004

40. Zarbakhsh S, Bakhtiyari M, Faghihi A, Joghataei MT, Mehdizadeh M, Khoei S, Mansouri K, Yousefi B, Pirhajati V, Moradi F: The effects of schwann and bone marrow stromal stem cells on sciatic nerve injury in rat: A comparison of functional recovery. Cell J (Yakhteh) 14:39, 2012

41. Zhang Z, Wang S, Tian X, Zhao Z, Zhang J, Lv D: A new effective scaffold to facilitate peripheral nerve regeneration: Chitosan tube coated with maggot homogenate product. Med Hypotheses 74: 12-14, 2010

42. Zou T, Ling C, Xiao Y, Tao X, Ma D, Chen ZL, Strickland S, Song $\mathrm{H}$ : Exogenous tissue plasminogen activator enhances peripheral nerve regeneration and functional recovery after injury in mice. J Neuropathol Exp 65:78-86, 2006 